\title{
Correction to: Study of the Effect of Geometric Parameters of Steel Block Slit Dampers on Energy Absorption
}

\author{
Peyman Katal Mohseni ${ }^{1} \cdot$ Amin Zahedi-khameneh $^{1} \cdot$ Omid Naeemifar $^{1}$
}

Published online: 7 July 2020

c) Korean Society of Steel Construction 2020

\section{Correction to: \\ International Journal of Steel Structures (2020) \\ 20(3):1069-1079. \\ https://doi.org/10.1007/s13296-020-00343-3}

In the original publication of the article, the caption of Figs. 2, 3, 4, 11 and 12 was published incorrectly. The correct caption should read as below.

Caption of Fig. 2 is "Method of imposing loads and boundary condition of damper".

Caption of Fig. 3 is "a The force-displacement verification of numerical BSD model and experimental results. b Shape displacement between experimental model of Amiri et al. (2018) and simulation".
Caption of Fig. 4 is "Loading displacement history (Amiri et al. 2018 after FEMA461 2007)".

Caption of Fig. 11 is "Backbone diagram of the b21 sample".

Caption of Fig. 12 is "Backbone diagram elicitation (Lee et al. 2016)".

In addition, the Fig. 18 should appear under the Sect. 8.

Publisher's Note Springer Nature remains neutral with regard to jurisdictional claims in published maps and institutional affiliations.

The original article can be found online at https://doi.org/10.1007/ s13296-020-00343-3.

Peyman Katal Mohseni

peyman.k.mohseni@gmail.com

1 Department of Civil Engineering, Malard Branch, Islamic Azad University, Malard, Iran 